\title{
The Alliance for Diversity in Science and Engineering: Empowering graduate students
}

Steven Lopez

Northeastern University, s.lopez@northeastern.edu

The Alliance for Diversity in Science \& Engineering is a national non-profit organization founded in 2015, whose mission is to lead a national diversity initiative and unite groups of graduate students to promote diversity and inclusion in STEM fields. Our executive board oversees and unites local, graduate student-run organizations that reach out to students and scientists of all ages and backgrounds. These local chapters develop vigorous outreach programs targeted for $\mathrm{K}-12$, community college, and/or undergraduate students. The national board connects scientists and engineers across the United States by creating opportunities to showcase non-traditional career paths and underrepresented minority experiences in STEM, as well as educate students about opportunities for scientists with graduate degrees. We organize and sponsor biannual Young Researcher Conferences, which are hosted at the universities where local chapters are housed. I will discuss the vision of this organization, the general structure of our local chapters and how they communicate with our board, and finally, the mission of these conferences, their evolution, and important student-driven future directions. 